\title{
Age differences in the allocation of study time account for age differences in memory performance
}

\author{
JOHN DUNLOSKY \\ University of North Carolina, Greensboro, North Carolina \\ and \\ LISA TABOR CONNOR \\ Boston University School of Medicine, Boston, Massachusetts
}

\begin{abstract}
How aging affects the utilization of monitoring in the allocation of study time was investigated by having adults learn paired associates during multiple study-test trials. During each trial, a subject paced the presentation of individual items and later judged the likelihood of recalling each item on the upcoming test; after all items had been studied and judged, recall occurred. For both age groups in Study 1, (1) people's judgments were highly accurate at predicting recall and (2) intraindividual correlations between judgments (or recall) on one trial, and study times on the next trial were negative, which suggests that subjects utilized monitoring to allocate study time. However, the magnitude of these correlations was less for older than for younger adults. Study 2 revealed that these differences were not due to age differences in forgetting. Results from both studies suggest that older adults do not utilize on-line monitoring to allocate study to the same degree as younger adults do, and that these differences in allocation contribute to age deficits in recall.
\end{abstract}

An almost universal finding is that verbal learning declines during normal aging. In comparison with younger adults, older adults require more study-test trials to attain a given level of performance (for reviews, see Arenberg \& Robertson-Tchabo, 1977; Kausler, 1994), and they may sometimes need more than twice as many studytest trials to attain the same level of performance that younger adults attain after only one (see, e.g., DelbecqDerouesné \& Beauvois, 1989; Korchin \& Basowitz, 1957; Salthouse \& Dunlosky, 1995). Much research on cognitive aging has been conducted to discover underlying cognitive deficits that mediate age-related differences in learning, whereas somewhat less research has been devoted to evaluating the contribution that metacognitive deficits make to these age-related declines. Our major aim was to evaluate whether aging affects the degree to which a person utilizes on-line monitoring of memory to allocate study time, an aspect of metacognition that may mediate age-related differences in memory performance.

\footnotetext{
This research was supported by the Southeastern Center for Applied Cognitive Aging Research, one of the Edward R. Roybal Centers for research in applied gerontology (funded through Grant 1 P50 AG1 181501 from NIA). The studies were conducted while the authors were supported as postdoctoral fellows at Georgia Institute of Technology by NIA Grant T32 AG00175-07. We thank C. Hertzog for continued discussion of this research, $\mathrm{K}$. Thiede for comments on earlier drafts of this article, and F. I. M. Craik, P. Dixon, and R. Dixon for helpful critiques. Send correspondence to J. Dunlosky, Department of Psychology, University of North Carolina at Greensboro, 296 Eberhart Bldg, Greensboro, NC 27412-5001 (e-mail: j-dunlos@goodall.uncg.edu).
}

To illustrate how this aspect of metacognition may mediate memory performance, we first describe a model of self-paced study (based on theory from Le Ny, Denhiere, \& Le Taillanter, 1972, and Nelson \& Narens, 1990). The model includes several metacognitive components central to the interplay between monitoring and control that occurs when an individual paces his/her own study. When studying an item, a person monitors memory of the item to form a perception of how it has been learned. The person compares this perceived degree of learning with the degree of learning desired for that item, which is a reference condition called the norm of study (Le Ny et al., 1972). When the perceived degree of learning is below the norm, the person will continue studying the item. By contrast, if the perceived degree of learning reaches or exceeds the norm of study, the person will terminate study and continue to the next item.

\section{Monitoring the Degree of Learning}

One implication of this model is that the accuracy of a person's monitoring will mediate memory performance (for empirical confirmation, see Bisanz, Vesonder, \& Voss, 1978; Maki \& Berry, 1984). In particular, people will spend more time studying items that they judge as less well known than items that they judge as well known, because they will typically require more time to achieve the norm of study for items that are further from the norm. Thus, if a person is inaccurate at judging which items he/she has learned well, that person may allocate too much time to items that he/she already knows well and not enough time to items that he/she knows less well. This 
rationale implies that if older adults are less accurate at monitoring memory than are younger adults, such differences may contribute to age-related differences in memory performance.

Accordingly, memory monitoring has been the focus of many investigations of aging and metamemory (e.g., Bieman-Copland \& Charness, 1994; Connor, Dunlosky, \& Hertzog, 1997; Lovelace \& Marsh, 1985; McDonaldMiszczak, Hubley, \& Hultsch, 1996; Rabinowitz, Ackerman, Craik, \& Hinchley, 1982; Shaw \& Craik, 1989). To evaluate whether age differences exist in the accuracy of monitoring, these investigators have usually employed a single study-test trial to examine the accuracy of people's predictions of learning. Items are first individually presented for study at a fixed rate. Some time after having studied a given item, the person makes a judgment of learning (JOL) for that item, which is a prediction about the likelihood of that person's correctly retrieving the item on the upcoming test. After all items have been studied, a test of memory is conducted. The accuracy of monitoring is then inferred from the degree to which people's JOLs predict memory performance.

Negligible age-related differences have been found in the accuracy of people's JOLs at predicting memory performance for one item relative to another (for a review, see Connor et al., 1997). On the basis of these findings, several researchers have argued that metamemory plays little or no role in mediating age differences in memory. For instance, Rabinowitz et al. (1982) reported that "both young and old adults were able to predict their ability to recall... [and hence] differences in metamemorial skills are not responsible for age differences in memory" (p. 688). Although such a conclusion arguably follows from some data on aging and metamemory (for similar conclusions, see Guttentag, 1985, Light, 1991, and Salthouse, 1991), it may be somewhat premature.

\section{Allocation of Self-Paced Study}

In particular, current conclusions about age-related effects on metamemory must be viewed as preliminary because the degree to which aging affects several components of metamemory has not yet been fully investigated (see Brigham \& Pressley, 1988, and Hultsch, Hertzog, \& Dixon, 1987, for discussion of components not considered here). For example, although age equivalence is typical in the accuracy of people's monitoring, age differences may be found in the degree to which people utilize that monitoring to allocate self-paced study to individual items.

On the basis of the aforementioned model, when an item is presented for self-paced study, a person assesses his/her own current degree of learning for the item and then utilizes this assessment in allocating study time. When a person has multiple study-test trials on which to learn items, two factors may be particularly relevant to this assessment of learning after the first trial: (1) monitoring that has occurred when a JOL was made for the item on a previous trial (Mazzoni \& Cornoldi, 1993), and (2) performance monitoring that has occurred during the recall attempt of the item on a previous test (King,
Zechmeister, \& Shaughnessy, 1980). An important point here is that these kinds of on-line monitoring can be the basis of highly accurate predictions of subsequent memory performance (Connor et al., 1997; Dunlosky \& Nelson, 1994; Nelson \& Dunlosky, 1991; Runquist, 1983). Therefore, utilizing the outcome of one's assessments of learning to allocate study time will presumably benefit learning, because doing so will allow an individual to focus restudy on less well known items rather than on more well known items (for evidence that younger adults benefit from utilizing JOLs to control study, see Mazzoni \& Cornoldi, 1993, Experiment 3, and Nelson, Dunlosky, Graf, \& Narens, 1994).

Our primary goal was to evaluate whether aging affects the degree to which monitoring is utilized to allocate study time across individual items, because agerelated deficits here may in turn contribute to age-related differences found in recall performance. To measure this kind of control process, we developed a multitrial task based on procedures used by Mazzoni and Cornoldi (1993). During a given study-test trial, each subject studied 60 paired-associate items (e.g., dog-spoon). Each subject studied an item as long as he/she wanted, and all subjects were instructed to master each item for the upcoming test (as in Nelson \& Leonesio, 1988). A JOL was also made for each item. After all items had been studied, paired-associate recall occurred for a subset of items. Next, another trial occurred in which all items were studied and judged again, and then a new subset of items was tested. This continued until all items had been tested. Two measures of allocation were then computed: (1) the correlation between JOLs on one trial and self-paced study on the next trial (without intervening recall), and (2) the correlation between recall on one trial and self-paced study on the next trial.

As discussed above, people were expected to allocate less study time to items that they judged as having been learned well than to items that they judged as having been learned less well, because the former will tend to require less time to reach the norm of study. This monitoringaffects-control hypothesis predicts that, across items, an inverse relation will occur between perceived degree of learning and subsequent allocation of study time (Nelson \& Leonesio, 1988). Namely, items that have been given higher JOLs (vs. lower JOLs) will later receive less study time, and items that have been recalled (vs. have not been recalled) will later receive less study time. These outcomes have been obtained with research involving younger adults (Mazzoni \& Cornoldi, 1993).

Will age-related differences occur in these measures of allocation? Craik (1986) hypothesized that older adults are less likely to self-initiate processes that would yield maximal memory performance. Such processes are central to the aforementioned model of self-paced study in which on-line decisions must be self-initiated to terminate study. Although we did not directly evaluate this general hypothesis of cognitive aging in the present research, one prediction here is that the magnitude of the relation between JOLs (or recall) on one trial and study 
time on the next trial will be less for older th $\lrcorner n$ for younger adults. At one extreme, older adults' JOLs (or recall) may show no relation to subsequent study time, which would disconfirm the monitoring-affects-control hypothesis for this age group.

To the degree that such control processes mediate subsequent memory, individual differences found in the allocation of study time were also expected to account for individual differences in recall performance. In the present context, regardless of why older adults are less fine tuned at allocating study time, such deficits may contribute to their poorer memory performance during self-regulated learning. Thus, given that age-related differences do occur in the aforementioned measures of allocation, a secondary goal of the present research was to evaluate whether individual differences in measures of allocation would account for any of the age-related variance found in recall performance (Salthouse, 1992).

These possibilities highlight the importance of examining the interplay among multiple components of metamemory. The literature on aging and metamemory is dominated by investigations of components of metamemory in isolation (for a discussion of some exceptions, see Hertzog \& Dunlosky, 1996). Such research is needed for the exploration of details of individual components of metamemory (see, e.g., Cavanaugh, 1996, for a review of the literature on memory self-efficacy and aging), but age deficits in metamemory that constrain memory performance may not emerge until theory is evaluated that describes how multiple components of metamemory interact to mediate performance. Although in the present research we investigated the relation between only two components, this research illustrates how on-line monitoring - an aspect of metamemory that has typically been investigated in isolation-may be involved in regulating a system that potentially contributes to age deficits in memory performance.

\section{STUDY 1}

\section{Method}

\section{Subjects, Apparatus, and Materials}

Eighty people participated: forty undergraduate students ( $M$ age $=$ 22) from the Georgia Institute of Technology and 40 older adults $(M$ age $=67)$ from the Atlanta metropolitan area. Each student received extra class credit, and each older adult received $\$ 10$.

Macintosh computers presented the items and instructions and recorded JOLs. The items were 68 word pairs composed of concrete ( $C \geq 6.08$; from the Paivio, Yuille, \& Madigan, 1968, norms), unrelated nouns (e.g., dog-spoon).

The subjects began by completing a demographic questionnaire and the Metamemory in Adulthood (MIA) questionnaire (Dixon \& Hultsch, 1984). Data from this questionnaire were generally consistent with previous research regarding age differences in means on scales of the MIA, but they did not add substantively to addressing the main questions of the present research. Thus, they are not reported here. Next, instructions and then self-paced learning occurred, followed by administration of the Advanced Vocabulary Test V4 from the ETS Reference Kit (Ekstrom, French, Harman, \& Dermen, 1976). Out of a maximum of 36 points, the mean number of points scored on the vocabulary test was 21 for older adults and
17 for younger adults $[t(78)=3.21, p<.05]$. The number of years of education was greater for the older adults $(M=15)$ than for the younger adults $(M=14)[t(78)=2.18, p<.05]$. All subjects reported being in relatively good health, and the number of medications that people reported using did not reliably differ between the older $(M=$ $1.28)$ and younger $(M=1.18)$ adults $[t(77)=.88]$.

\section{Procedure}

The task included three critical study-test trials; JOLs were made during the study trials. Prior to these trials, the subjects read detailed instructions about the task and then practiced pacing the presentation of items during study and making JOLs. Items used for practice were not included during the critical trials. The subjects were encouraged to ask questions during instructions and practice, and they did not proceed to the critical trials until they understood the task.

During a given study trial, each item was presented individually for self-paced study. An item remained on the computer screen for study until the subject pressed "Return," at which time the item was replaced either by the next item to be studied or by a cue for a JOL. To obtain a relatively noise-free measure of study time, we had subjects keep a finger on the "Return" key while an item was presented during study. The subjects were instructed to study each item as long as they needed so that they would recall the item on the upcoming test, but not to waste time, because the time required for study also reflected how efficiently they were learning the list (instructions adapted from Mazzoni, Cornoldi, \& Marchitelli, 1990). Study time was recorded by the computer to the nearest $1 / 60$ of a second.

The order of presentation of items for study was randomized anew for each study trial, with the only restriction being that at least 10 items in the first (and second) half of the list had not been previously tested. This restriction ensured that 10 items from each half of the list would be available for testing (i.e., only 20 items were tested on each trial, as described below). During each study trial, the subjects also made a self-paced JOL for each of the 60 critical items. JOLs were cued by the stimulus alone (e.g., if dog-spoon had been presented for study, dog-? would be the cue for the JOL). This cue was presented below the following statement: "Please make rating for item below." When they made a JOL, the subjects were instructed to rate how confident they were in recalling the second word of the item when the first word was presented on the next test trial. JOLs were made on a 6-point predicted likelihood scale: $0=$ definitely will not recall the second word, $20=20 \%$ sure I will recall the second word, $40=40 \%$ sure, $60=60 \%$ sure, $80=80 \%$ sure, and $100=$ definitely will recall the second word.

JOLs were delayed until after the study of items by alternating study and JOLs: After an item had been studied, 8 other items were presented for study (as well as the JOLs for previously studied items), and then the JOL cue was presented for that item. Delayed JOLs were used because they are highly accurate predictors of upcoming memory performance (see, e.g., Dunlosky \& Nelson, 1992); hence, utilizing such monitoring is likely to benefit the allocation of study time. The 8-item lag between the study and JOL for each of the 60 critical items was ensured by presenting 8 filler items at the end of each study trial. These filler items were not rated and did not appear on the test trials

Each of the three study trials (which consisted of study and delayed JOLs for all of the 60 critical items) was followed by pairedassociate recall for 20 of the 60 critical items. Only a third of the items were tested on each trial, so that the relation between JOLs and self-paced study could be assessed for items that had not been previously tested. The subjects were not told that each item would be tested only once. Items were selected for testing as follows: After the first study trial, 10 items were randomly selected from the first 30 items presented for study during that trial, and 10 items were randomly selected from the second half of the items. The order of these 20 items was then randomized for testing. For each of these items, the stimulus was presented, and the subjects wrote a response 
on an answer sheet. The subjects were encouraged to respond but were allowed to omit an answer. The subjects proceeded to the next to-be-tested item by pressing a computer key.

The 20 items that had been tested during the first trial were not presented for testing on the other trials, so that each item was presented for recall only once. After the second study trial, recall occurred for 20 of the items that had not been previously tested; items were selected and presented for test trials as described above. After the third study trial, recall occurred for the remaining 20 critical items.

\section{Results and Discussion}

\section{Recall Performance}

For each subject, the percentage of items correctly recalled was calculated for each of the three test trials. The means across individuals are plotted (filled symbols) as a function of trial in Figure 1.

Recall performance for both age groups improved across trials and was significantly greater for younger adults than for older adults. ${ }^{1}$ As is shown in Figure 1, older adults required three self-paced study trials to attain the same level of recall performance that younger adults had after only one study trial. Such age-related differences are at least as large as those found in investigations in which the presentation rate of items is paced by the experimenter (cf. results described by Kausler, 1994, pp. 73-76).

\section{Judgments of Learning}

Relative accuracy of the judgments of learning. To assess the degree to which people accurately predicted the likelihood of recall performance for one item relative to another, we computed Goodman-Kruskal gamma

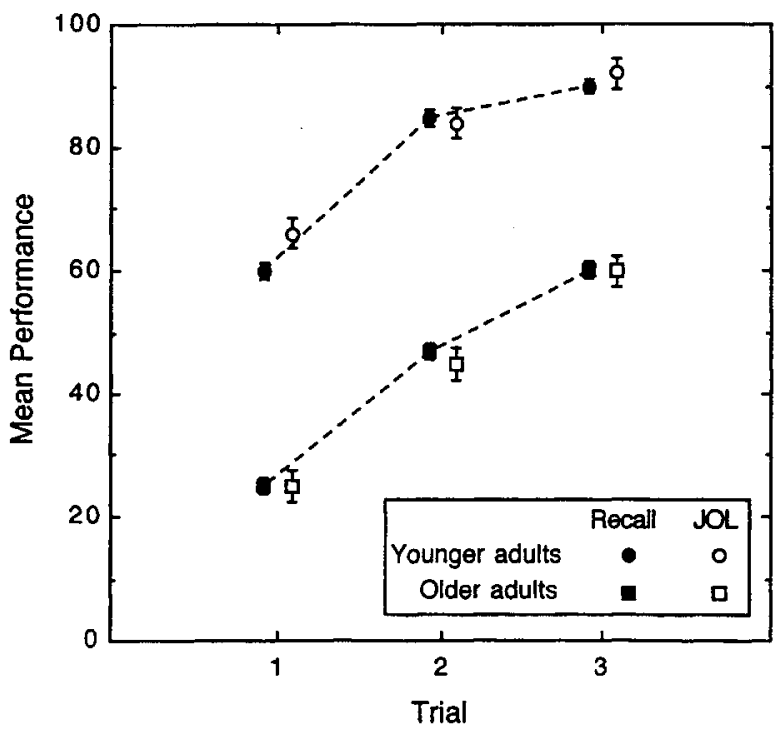

Figure 1. For Study 1, means across individuals' mean percentage of correct recall (filled symbols) and across individuals' median judgments of learning (JOL; unfilled symbols) plotted separately for younger (circles) and older (squares) adults. Bars shown correspond to the standard error of the means for trial to emphasize the within-subjects comparison between recall and JOLs. Standard errors for age group were 6.5 for recall and 8.2 for JOLs. correlations between each subject's JOLs and recall performance. For each subject, three gamma correlations were computed: one for each study-test trial between the JOLs and recall performance on that trial. The medians across individuals' correlations for each of the six conditions ( 2 age groups $\times 3$ trials) were all above +.93 . Thus, negligible age-related differences were found in the relative accuracy of people's JOLs, and both age groups were highly accurate at predicting recall performance during each of the three trials.

Absolute accuracy of the judgments of learning. $\mathrm{Ab}$ solute accuracy is the degree to which a person predicts the actual percentage of correct recall for a set of items. One way to operationalize absolute accuracy is to compare the level of predicted performance on a given trial with the actual percentage of correct recall on that trial. In terms of multitrial learning, perfect absolute accuracy at predicting performance across trials would be represented by the mean JOL directly overlapping mean recall across all trials.

To evaluate absolute accuracy, we computed the means across individuals' median JOLs on a given trial (computed for only the 20 items that were tested on each trial) and then plotted these values (unfilled symbols) beside the corresponding values of actual recall performance (filled symbols) in Figure 1. As is evident from inspection of this figure, although age-related differences occurred in the magnitude of JOLs, absolute accuracy was high across all three trials, with no systematic differences occurring between predicted recall (JOL) and actual recall for both age groups.

Because the lack of age-related differences here may in part be an artifact of averaging across subjects' scores, absolute accuracy was also evaluated at the level of individuals by examining the least squares linear equation of best fit across individuals' mean JOLs and mean recall. If absolute accuracy is perfect at this level of analysis, the parameters of this equation will correspond to $y=0.0+1.0 x$, where $x$ is an individual's predicted recall (mean JOL) and $y$ is the individual's mean recall. No systematic differences in parameters occurred across trials or between age groups, with mean values across trials yielding equations of $y=32+.57 x(r=.67)$ for younger adults and $y=20+.55 x(r=.79)$ for older adults.

\section{Self-Paced Study}

Relation between judgments of learning and selfpaced study. To evaluate the monitoring-affects-control hypothesis, for each subject a Goodman-Kruskal gamma correlation was computed between JOLs on one trial and self-paced study on the next trial. One gamma was computed between JOLs on Trial 1 and study times on Trial 2 for the 20 items that were subsequently tested on Trial 2 , and another was computed between JOLs on Trial 2 and study times on Trial 3 for the 20 items that were subsequently tested on Trial 3 . The means across individuals' gamma correlations are reported in the top panel of Figure 2. 


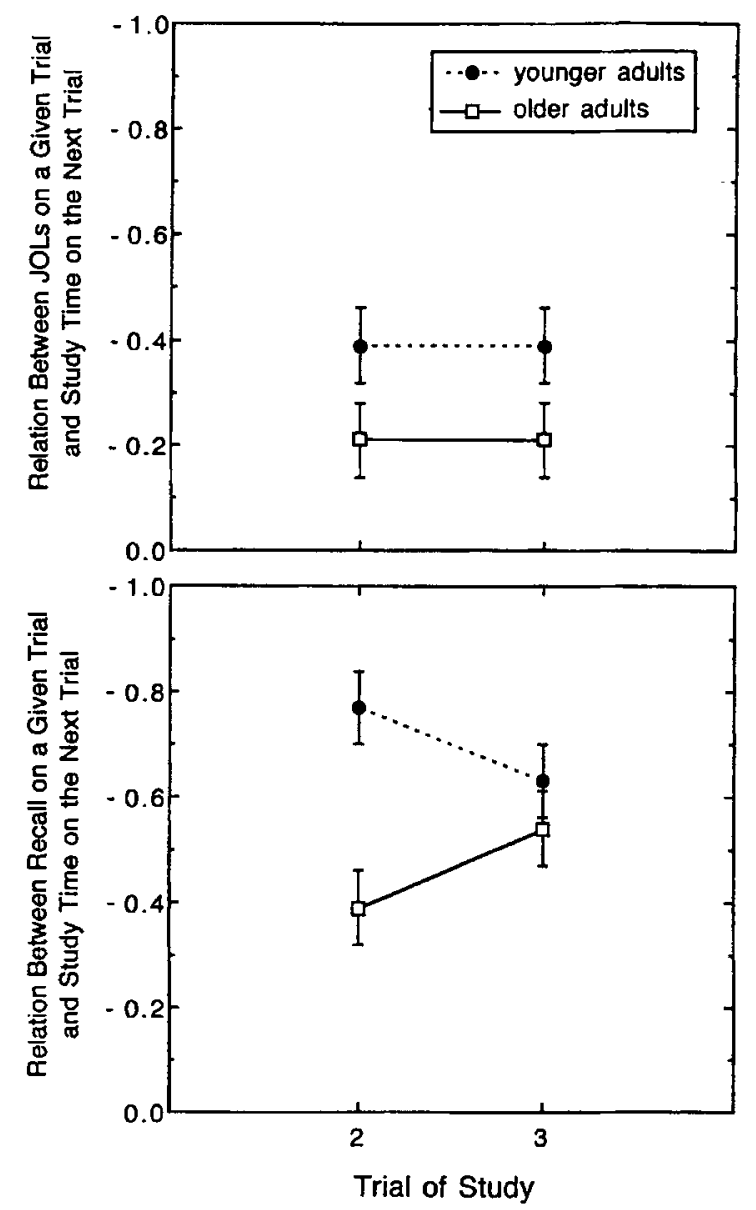

Figure 2. For Study 1, means across individuals' correlation (1) between judgments of learning (JOLs) on a trial and selfpaced study on the next trial (top panel) and (2) between recall on a trial and self-paced study on the next trial (bottom panel). Values on the horizontal axis were labeled with the trial number of study to emphasize that the focus here is on how people allocated study time on that trial. Bars shown correspond to the standard error of the means for age group. Standard error of the means for trial was.03.

Results in Figure 2 confirm the monitoring-affectscontrol hypothesis: Both age groups spent more time studying items that had been judged as less likely to be recalled than as more likely to be recalled. However, the magnitude of the correlation was significantly greater for younger adults than for older adults, which suggests age-related differences occurred in the degree to which monitoring was utilized to allocate study time across items.

Relation between recall performance and self-paced study. The monitoring-affects-control hypothesis was also evaluated by examining the relation between recall performance on a trial and self-paced study on the next trial (as in Mazzoni \& Cornoldi, 1993). One gamma was computed between recall performance on Trial 1 and study times on Trial 2 for the 20 items that were tested on Trial 1, and one was computed between recall performance on Trial 2 and study times on Trial 3 for the 20 items that were tested on Trial 2. The mean across individuals' correlations are presented in the bottom panel of Figure 2.

The negative correlations shown in the bottom panel of Figure 2 indicate that both younger adults and older adults allocated more study time to items that had not been recalled than to items that had been recalled. The magnitude of these correlations was greater for younger adults than for older adults, but this difference was not statistically significant on the third trial. Although the smaller effect size for Trial 3 may have occurred in part because many younger adults had close-to-ceiling recall performance, this possibility cannot account for the increase that the older adults' correlation showed across trials. However, because this interaction was not replicated in Study 2, we discuss it no further here.

\section{Regression Analyses}

A secondary goal of the present research was to examine whether age-related differences in people's allocation of study time (as reflected in the relation between on-line monitoring and self-paced study) may mediate any agerelated differences in recall performance. To provide an answer to this question, we compared the total amount of variance in recall associated with age and the amount of variance in recall associated with age after partialling for a measure of allocation (for a detailed discussion of this kind of regression analysis, see Salthouse, 1992). If the allocation of study time mediates none of the age-related differences in recall, partialling the allocation-related variance from recall will not affect the degree with which age is related to recall. By contrast, if the allocation of study time mediates age-related differences in recall, removing the allocation-related variance from recall will significantly reduce the relation between age and recall.

This analysis focuses on accounting for age-related variance in recall on Trial 2 because performance on this trial was intermediate for both age groups. Also, the same conclusions were obtained regardless of which measure of allocation was evaluated, so we report results from only the analysis that included the measure of allocation involving recall. The total amount of variance in recall associated with chronological age was $.34\left(\beta_{\text {age }}=-.58\right.$, $p<.05$ ). After partialling for the correlation between recall on Trial 1 and self-paced study on Trial 2, the change in $R^{2}$ for adding age was .08 $\left(\beta_{\text {age }}=-.31, p<.05\right)$. Accordingly, partialling for a measure of allocation reduced the age-related variance in recall by $76 \%$ [i.e., $\left(R^{2}\right.$ with age alone $-R^{2}$ change) $/ R^{2}$ with age alone]. These outcomes are consistent with the notion that the degree to which individuals utilize monitoring to allocate study time contributes to age-related deficits in recall.

\section{STUDY 2}

One explanation for the age-related differences in the measures of allocation (Figure 2) is based on the hypothesis that memory for contextual information declines with aging in adulthood (for a review, see Spencer \& 
Raz, 1995). In the present case, monitoring that occurs during a given trial is context relative to the more central focus of learning and recalling the items; hence, aging may increase the likelihood that monitoring during a given trial will be forgotten before the next study trial. If so, older adults will less often have access to previous monitoring when they begin studying an item, which will yield lower relations between measures of monitoring and study time.

We examined this possibility in Study 2 by presenting the outcome of recall on a trial during the next study trial. If the response of an item had not been correctly recalled, the prompt "NOT Correctly Recalled" was shown immediately before that item was presented for study on the next trial. If the response had been recalled, the prompt "CORRECTLY recalled" was shown. If age-related differences in the relation between recall and self-paced study (bottom panel of Figure 2) are caused by forgetting this information, providing it prior to study will yield age equivalence in the relation between recall and study times. By contrast, age-related differences will persist between JOLs and study time because JOLs made on a given trial were not re-presented during the next trial.

\section{Method}

\section{Subjects, Apparatus, and Materials}

Ninety-five people participated: 50 undergraduate students $(M$ age $=21)$ from the Georgia Institute of Technology and 45 older adults $(M$ age $=69)$ from the Atlanta metropolitan area. There was no overlap of subjects from Studies 1 and 2. Each student received extra class credit, and each older adult received $\$ 10$.

The apparatus and materials were identical to those used in Study 1, the one exception being that the MIA questionnaire was not admin- istered, in order to ensure that every subject finished the learning trials within $2 \mathrm{~h}$. The mean number of points scored on the vocabulary test was 21 for older adults and 16 for younger adults $[t(93)=$ 4.37]. The number of years of education was greater for older $(M=$ $15)$ than for younger $(M=14)$ adults $[t(93)=1.99]$. All subjects reported being in relatively good health, and the number of medications that people reported using did not reliably differ between older $(M=1.29)$ and younger $(M=1.14)$ adults $[t(93)=1.79]$.

\section{Procedure}

In contrast to the task in Study 1, the task in Study 2 included four (instead of three) critical study-test trials so that we could examine older adults' allocation over a broader range of performance. Delayed JOLs were made during the study trials. Study trials occurred as in Study 1, with the following exceptions. First, immediately prior to the onset of the presentation of an item for study, one of the following three prompts was presented for $1.5 \mathrm{sec}$ (depending on the outcome of the immediately previous test trial): (1) "CORRECTLY Recalled" (the to-be-studied item had been correctly recalled), (2) "NOT Correctly Recalled" (the to-be-studied item had not been correctly recalled), and (3) "****" (the to-be-studied item had not been tested). Before the critical study-test trials, the prompts were described in detail. The subjects were instructed that the prompt signified what had actually happened on the previous test trial and that it was presented to help them get ready to study the next item. The subjects were not told that the prompts could be used, or how they could be used, to allocate their study. Practice trials occurred as in Study 1 and included the prompt of asterisks. Items were randomized anew for each study trial, with the restriction that approximately half of the items that had not yet been tested were slated to be studied in the first 30 items.

Second, each of the four study trials was followed by pairedassociate recall of 15 of the 60 critical items. Thus, on each study trial after the first recall trial, the prompt of asterisks was presented before the 45 items that had not been tested on the previous trial, and the two other prompts were presented for the 15 items that had just been tested. Items were selected for testing as follows: After the

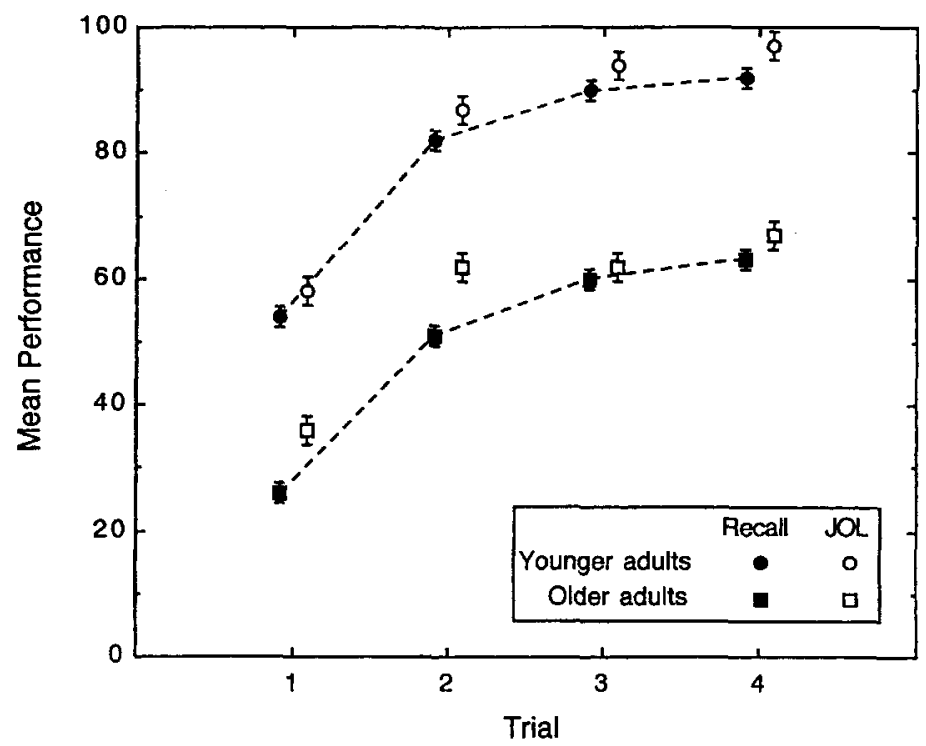

Figure 3. For Study 2, means across individuals' mean percentage of correct recall (filled symbols) and across individuals' median judgments of learning (JOL; unfilled symbols) plotted separately for younger (circles) and older (squares) adults. Bars shown correspond to the standard error of the means for trial to emphasize the within-subjects comparison between recall and JOLs. Standard errors for age group were 6.9 for recall and 8.6 for JOLs. 
first study trial, 7 items were randomly selected from the first 30 items presented for study during that trial, and 8 items were randomly selected from the second half of items. The order of these 15 items was then randomized for testing, and the test trials occurred as in Study 1 , except that the subjects typed their responses on the computer keyboard. The subjects had to type their responses so that they could be scored on line, which enabled the computer to present the appropriate prompt during the next study trial. The subjects were instructed to use as much time as they needed to accurately type responses; the role of spelling errors was also minimized by scoring a response as correct if its first three letters were correct.

\section{Results and Discussion}

\section{Recall Performance}

For each subject, the percentage of correct recall performance was calculated for each of the four test trials. The means across individuals are plotted (filled symbols) in Figure 3. As in Study 1, recall performance improved across trials and was greater for younger adults than for older adults.

\section{Judgments of Learning}

Relative accuracy of the judgments of learning. For each subject, Goodman-Kruskal gamma correlations were computed between JOLs and recall performance on each of the four trials. The median correlations for each of the eight conditions were all above +.89 . Thus, as in Study 1 and in previous research (Connor et al., 1997), age-related differences in the relative accuracy of JOLs were negligible.

Absolute accuracy of the judgments of learning. The mean across individuals' median JOLs was computed for each trial and then plotted (unfilled symbols) beside the corresponding values of actual recall performance in Figure 3. Although the magnitude of JOLs was close to the level of recall for most trials, both younger adults and older adults appeared to overestimate the level of recall performance on earlier trials.

As in Study 1, absolute accuracy was also evaluated by examining the least squares linear equation of best fit across individuals' mean recall and mean JOLs. No systematic differences in parameters occurred across trials or between age groups, with mean values across trials yielding equations of $y=6.1+.91 x(r=.83)$ for younger adults and $y=-0.87+.91 x(r=.89)$ for older adults.

\section{Self-Paced Study}

Relation between judgments of learning and selfpaced study. We computed a Goodman-Kruskal gamma correlation between JOLs on one trial and self-paced study time on the next trial as in Study 1 (i.e., each gamma for a given trial included the 15 items that were tested on the next trial). The means across individuals' gamma correlations are shown in the top panel of Figure 4.

The negative correlations indicate that subjects spent more time studying items that had been judged as less likely to be recalled than they did studying items judged as more likely to be recalled. Although the age-related effects were not statistically significant for each trial, con-

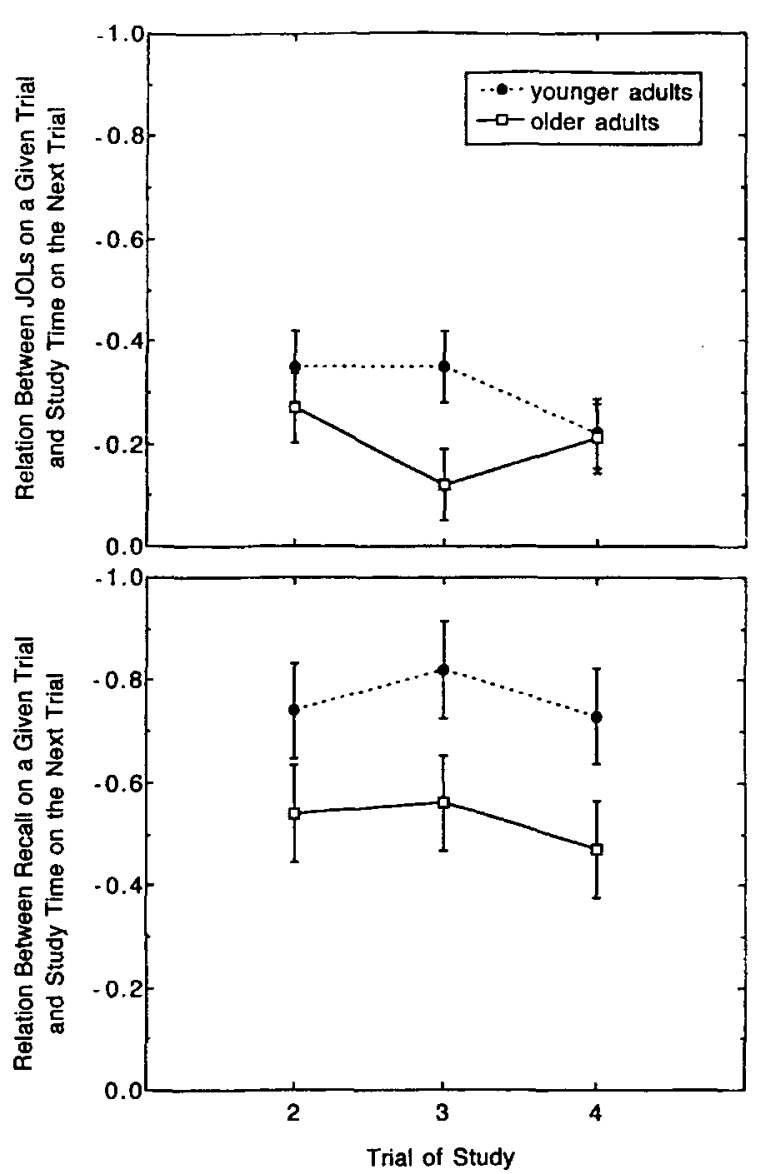

Figure 4. For Study 2, means across individuals' correlation (1) between judgments of learning (JOLs) on a trial and selfpaced study on the next trial (top panel) and (2) between recall on a trial and self-paced study on the next trial (bottom panel). Values on the horizontal axis were labeled with the trial number of study to emphasize that the focus here is on how people allocated study time on that trial. Bars shown correspond to the standard error of the means for age group. Standard error of the means for trial was .03.

sistency among results was high from Study 2 and Study 1 (except for the value of -.22 on Trial 4 for the younger adults, which may have been attenuated because of closeto-ceiling JOLs).

Relation between recall performance and self-paced study. Three gamma correlations were computed between recall performance on one trial and self-paced study on the next trial as in Study 1. The means across individuals' gamma correlations are shown in the bottom panel of Figure 4. Two outcomes are evident from inspection of this figure. First, both age groups allocated more study time to items that had not been recalled than to items that had been recalled. Second, age-related differences were consistent across trials even though the subjects were told at the time of study which items had been recalled and which had not been recalled. Thus, any age-related differences in remembering the history of an item cannot account for age differences in allocation. 


\section{Regression Analyses}

As in Study 1, we examined whether age-related variance in recall performance on Trial 2 could be accounted for by individual differences in a measure of study-time allocation. If study-time allocation mediates the relation between age and recall, age-related variance in recall will be attenuated when the measure of allocation is entered into the regression equation before age is entered relative to when only age is entered into the regression equation. The total amount of variance in recall associated with age was $.24\left(\beta_{\text {age }}=-.49, p<.05\right)$. After partialling for the correlation between recall on Trial 1 and self-paced study on Trial 2 , the change in $R^{2}$ for adding age was $.10\left(\beta_{\text {age }}=-.33, p<.05\right)$. Therefore, partialling out the measure of allocation reduced the age-related variance in recall by $57 \%$. These outcomes are consistent with the notion that the degree to which individuals utilize monitoring to allocate study time contributes to agerelated deficits in recall.

\section{GENERAL DISCUSSION}

In the present research, we investigated how aging affects components of metacognition that potentially interact to mediate memory performance during self-paced study. One of the components investigated here, metacognitive monitoring, has received much attention in the area of aging and metamemory (Hertzog \& Dixon, 1994). Consistent with previous results from this literature, we found negligible age-related differences in the accuracy of people's JOLs at predicting recall performance. This outcome provides converging evidence for earlier conclusions made by Rabinowitz et al. (1982) and others. Namely, given age equivalence in JOL accuracy with concurrent differences in recall, the accuracy of metacognitive monitoring plays little role in mediating agerelated differences in learning.

With regard to the process of allocation of study time, both relative JOL accuracy and absolute JOL accuracy were substantial for both age groups, suggesting that utilizing the output of monitoring to allocate study time would benefit memory performance. Although measures of monitoring were related to subsequent allocation of study time for both age groups, age-related differences in the magnitude of these relations were the norm. These effects suggest that older adults utilize the output from monitoring to control study to a lesser degree than do younger adults. One explanation for such differences is that older adults (as compared with younger adults) are more likely to forget the output from monitoring on previous trials, and hence they are less able to utilize this monitoring to allocate study time. In contrast to this hypothesis, evidence from Study 2 indicates that age differences in forgetting will not completely account for the present effects, because even when the presumed outcome of performance monitoring was provided immediately before an item was restudied, older adults did not utilize that information to the same degree as did younger adults.
Age-related differences in the placement of the norm of study are also unlikely to account for the age-related differences in allocation. In particular, subjects were instructed to master the entire list of items, which presumably would yield a high norm of study for both age groups. It is possible that the instructions to master the entire list of items may have been offset by age-related differences in memory self-efficacy. That is, because older adults believe that they have less ability to successfully accomplish memory-related tasks (Cavanaugh, 1996; Hertzog \& Dixon, 1994), they may have set a somewhat lower norm of study for each item. However, even if such differences had occurred, consideration of the model of selfpaced study suggests that they would have had a minimal effect on the relation between monitoring and study time.

Consistent with this possibility, instructions that presumably have a substantial impact on individuals' norm of study have had little to no effect on correlational measures of allocation. Nelson and Leonesio (1988) had younger adults pace their study either under instructions to learn a list as quickly as possible (speed instructions) or under instructions to master a list of items (mastery instructions). Overall study time was nearly half as long for subjects who had speed instructions than for those who had mastery instructions, suggesting that the norm of study was lower for the speed group (cf. the potentially lower norm of study for older than for younger adults). However, the magnitude of correlations between monitoring judgments and study time was greater after speed instructions than after mastery instructions, which is the opposite of that which would be expected if setting a lower norm reduces one's utilization of monitoring to allocate study time. Therefore, even if older adults had consistently set a lower norm of study than did younger adults, such differences would not necessarily have caused the present age-related effects.

Another possibility is that the age-related differences in allocation do not directly reflect age-related declines either in cognitive processes or in metacognitive processes. Instead, they may reflect controlled processes used by older adults to compensate for declines in memory (see Bäckman \& Dixon, 1992, for a detailed development of psychological compensation). For instance, older adults may believe that they can master only a few items of a list. As a result, they may have occasionally restudied items judged as already well learned to ensure that they would have mastered at least some. The use of such a strategy to compensate for memory decline may be somewhat ironic in the present task, because it may not compensate for age-related differences in learning but instead contribute to them.

Accordingly, this kind of compensation may help explain why individual differences in the measures of allocation accounted for age-related variance in recall. Namely, if older adults attempted to compensate for perceived declines in memory, they may have spent too much time studying already well-known items. Although this may have enhanced memory for a small subset of 
items, it may have been at the expense of not learning less well known items. This illustrates that discovering why study-time allocation accounts for age-related variance in recall will depend critically on understanding how aging affects allocation per se. Another possibility here is that older adults may be less likely to self-initiate the coordination of on-line monitoring and control processes that are required to effectively allocate study time (Craik, 1986). If so, older adults may terminate study prior to reaching the norm of study for some items (which would reduce the likelihood of recalling them) and terminate study time some time after the norm had been reached for others (which may reduce the likelihood of recall for other items). Given the central role of self-regulated learning for everyday memory, evaluating these and other possibilities provides an important challenge for future investigations of aging and self-paced study.

In conclusion, the present research contributes to the literature on aging and metacognition in several ways. A procedure was introduced that will allow researchers to evaluate how aging affects people's allocation of study time to individual items. Results here suggest that allocation of study time to paired-associate items is less fine tuned for older than for younger adults, although the cause of these differences is currently unknown. Correlational evidence from both studies also implies that age differences in study-time allocation contribute to age deficits in memory performance. Finally, the model of self-paced study described here provides a framework to help guide research on the interplay among numerous components of metacognition, such as on-line monitoring, memory self-efficacy, and self-paced study. Further investigations of how such components jointly determine self-regulated learning will be essential for understanding how metacognition contributes to age deficits in memory.

\section{REFERENCES}

Arenberg, D., \& Robertson-TChabo, E. E. (1977). Learning and aging. In J. E. Birren \& K. W. Schaie (Eds.), Handbook of the psychology of aging (pp. 421-449). New York: Van Nostrand Reinhold.

BÄCKMAN, L., \& DixON, R. A. (1992). Psychological compensation: A theoretical framework. Psychological Bulletin, 112, 259-283.

Bieman-Copland, S., \& Charness, N. (1994). Memory knowledge and memory monitoring in adulthood. Psychology \& Aging, 9, 287-302.

Bisanz, G. L., Vesonder, G. T., \& Voss, J. F. (1978). Knowledge of one's own responding and the relation of such knowledge to learning. Journal of Experimental Child Psychology, 25, 116-128.

Brigham, M. C., \& Pressley, M. (1988). Cognitive monitoring and strategy choice in younger and older adults. Psychology \& Aging, 3, 249-257.

Cavanaugh, J. C. (1996). Memory self-efficacy as a moderator of memory change. In F. Blanchard-Fields \& T. M. Hess (Eds.), Perspectives on cognitive change in adulthood and aging (pp. 488-507). New York: McGraw-Hill.

Connor, L. T., Dunlosky, J., \& Hertzog, C. (1997). Age-related differences in absolute but not relative metamemory accuracy. Psychology \& Aging, 12, 50-71

Craik, F. 1. M. (1986). A functional account of age differences in memory. In F. Klix \& H. Hagendorf(Eds.), Human memory and cognitive capabilities: Mechanisms and performances (pp. 409-422). Amsterdam: Elsevier, North-Holland.
DelbecQ-Derouesné, J., \& Beauvols, M. (1989). Memory processes and aging: A defect of automatic rather than controlled processes? Archives of Gerontology \& Geriatrics, 1(Suppl.), 121-150.

Dixon, R., \& Hultsch, D. (1984). The Metamemory in Adulthood (MIA) instrument. Psychological Documents, 14, 3.

Dunlosky, J., \& Nelson, T. O. (1992). Importance of the kind of cue for judgments of learning (JOL) and the delayed-JOL effect. Memory \& Cognition, 20, 374-380.

Dunlosky, J., \& NELSON, T. O. (1994). Does the sensitivity of judgments of learning (JOLs) to the effects of various study activities depend on when the JOLs occur? Journal of Memory \& Language, 33, 545-565.

EKstrom, R. B., FrenCh, J. W., Harman, H. H., \& Dermen, D. (1976). Manual for kit of factor-referenced cognitive tests. Princeton, NJ: Educational Testing Service.

GUTTENTAG, R. E. (1985). Memory and aging: Implications for theories of memory development during childhood. Developmental Review, 5, 56-82.

HerTZOG, C., \& Dixon, R. (1994). Metacognitive development in adulthood and old age. In J. Metcalfe \& A. P. Shimamura (Eds.), Metacognition: Knowing about knowing (pp. 227-251). Cambridge, MA: MIT Press.

Hertzog, C., \& Dunlosky, J. (1996). The aging of practical memory: An overview. In D. J. Hermann, C. McEvoy, C. Hertzog, P. Hertel, \& M. K. Johnson (Eds.), Basic and applied memory (Vol. 1, pp. 337358). Mahwah, NJ: Erlbaum.

Hultsch, D. F., Hertzog, C., \& Dixon, R. A. (1987). Age differences in metamemory: Resolving the inconsistencies. Canadian Journal of Psychology, 41, 193-208.

KAUSLER, D. H. (1994). Learning and memory in normal aging. New York: Academic Press.

King, J. F., Zechmeister, E. B., \& Shaughnessy, J. J. (1980). Judgments of knowing: The influence of retrieval practice. American Journal of Psychology, 93, 329-343.

KorChIN, S. J., \& Basowitz, H. (1957). Age differences in verbal learning. Journal of Abnormal \& Social Psychology, 54, 64-69.

Le Ny, J. F., Denhiere, G., \& Le Taillanter, D. (1972). Regulation of study-time and interstimulus similarity in self-paced learning conditions. Acta Psychologica, 36, 280-289.

LiGHT, L. L. (1991). Memory and aging: Four hypotheses in search of data. Annual Review of Psychology, 42, 333-376.

Loftus, G. R., \& Masson, M. E. J. (1994). Using confidence intervals in within-subject designs. Psychonomic Bulletin \& Review, 1, 476-490.

Lovelace, E. A., \& Marsh, G. A. (1985). Prediction and evaluation of memory performance by young and old adults. Journal of Gerontology, 40, 192-197.

MAKI, R. H., \& BERRY, S. L. (1984). Metacomprehension of text material. Journal of Experimental Psychology: Learning, Memory, \& Cognition, 10, 663-679.

Mazzoni, G., \& CoRnoldi, C. (1993). Strategies in study time allocation: Why is study time sometimes not effective? Journal of Experimental Psychology: General, 122, 47-60.

Mazzoni, G., Cornoldi, C., \& Marchitelli, G. (1990). Do memorability ratings affect study-time allocation? Memory \& Cognition, 18, 196-204.

MCDonald-Miszczak, L., Hubley, A. M., \& Hultsch, D. F. (1996). Age differences in recall and predicting recall of action events and words. Journal of Gerontology: Psychological Sciences, 51, 81-90.

Nelson, T. O., \& DUNLOSKY, J. (1991). When people's judgments of learning (JOLs) are extremely accurate at predicting subsequent recall: The "delayed-JOL effect." Psychological Science, 2, 267-270.

Nelson, T. O., Dunlosky, J., Graf, A., \& Narens, L. (1994). Utilization of metacognitive judgments in the allocation of study during multitrial learning. Psychological Science, 5, 207-213.

Nelson, T. O., \& LEONESIO, R. J. (1988). Allocation of self-paced study time and the "labor-in-vain effect." Journal of Experimental Psychology: Learning. Memory, \& Cognition, 14, 676-686.

Nelson, T. O., \& Narens, L. (1990). Metamemory: A theoretical framework and new findings. In G. H. Bower (Ed.), The psychology of learning and motivation (Vol. 26, pp. 125-173). New York: Academic Press. 
Paivio, A., Yuille, J. C., \& Madigan, S. A. (1968). Concreteness, imagery, and meaningfulness values for 925 nouns. Journal of Experimental Psychology Monographs, 76 (1, Pt. 2).

Rabinowitz, J. C., Ackerman, B. P., Craik, F. I. M., \& Hinchley, J. L. (1982). Aging and metamemory: The roles of relatedness and imagery. Journal of Gerontology, 37, 688-695.

RUNQUisT, W. N. (1983). Some effects of remembering on forgetting. Memory \& Cognition, 11, 641-650.

SALThouse, T. A. (1991). Theoretical perspectives on cognitive aging. Hillsdale, NJ: Erlbaum.

SALTHOUSE, T. A. (1992). Mechanisms of age-cognition relations in adulthood. Hillsdale, NJ: Erlbaum.

Salthouse, T. A., \& Dunlosky, J. (1995). Analyses of adult age differences in associative learning. Zeitschrift für Psychologie, 203, 351-360.

ShaW, R., \& CraIK, F. I. M. (1989). Age differences in predictions and performance on a cued recall task. Psychology \& Aging, 4, 131-135.
SPENCER, W. D., \& RAZ, N. (1995). Differential effects of aging on memory for context and content: A meta-analysis. Psychology \& Aging, 10, 527-539.

\section{NOTE}

1. Analysis of data in both experiments is based on standard errors of the means reported with each figure. To allow comparisons either between age groups or across trials, standard errors are reported both for the between-subjects variable of age group and for the within-subjects variable of trial (Loftus \& Masson, 1994). Differences declared as significant were also substantiated by inferential tests (e.g., analysis of variance and $t$ tests) in which $p<.05$.

(Manuscript received January 18, 1996; revision accepted for publication September 20, 1996.)

\section{Workshop on Representation and Blindness San Marino, Republic of San Marino May 22-23, 1998}

The workshop will include invited and other presentations by researchers in the field of touch, perception, and cognition, with special relevance to blindness. The meeting will be open to interested parties from a variety of disciplines within the sphere of perceptual and cognitive processes in blindness. We will consider abstracts for brief oral presentations and posters that involve theoretical and applied work. Send abstracts, if possible, by October 15, 1997.

San Marino is the capital of the Republic of San Marino, a small state located in central Italy. For further information, please contact the organizers of the workshop, by e-mail if possible: Cesare Cornoldi, Dipartimento di Psicologia Generale, Piazza Capitaniato 3, 35139 Padova, Italy (e-mail: cornold@psico.unipd.it) or Morton A. Heller, Psychology, Winston-Salem State University, Winston-Salem, NC 27110, U.S.A. (e-mail: mheller@ols.net). 